Hanging of the Crane,' and 'Morituri Salutamus.' Portions of the 'Building of the Ship' have been quite extensively used in schools, but the whole poem has never appeared before in so cheap a form. To those who have read (and who have not?) the 'Paradise for Children' in Hawthorne's 'Wonder Book' (see number I7 of the same series), which tells the story of Pandora's Box, the 'Masque of Pandora' will be especially interesting. The 'Morituri Salutamus' was written for the celebration of the fiftieth anniversary of Longfellow's graduation from Bowdoin College, and is considered one of his best poems. 'The Hanging of the Crane' is too well known to need more than a passing mention. These poems, while simple enough for children of the Fourth Reader grade, will be enjoyed by all lovers of Longfellow, and by all admirers of good poetry. These poems are accompanied by very carefully prepared notes, which, without being voluminous, will be found helpful at just the places where help is needed.

- In Science, No. 299, page I98, first column, I4th line from the top of the page, for 'house-leek,' read 'hawk-weed.'

LETTERS TO THE EDITOR.

On Alleged Mongoloid Traits in the American Race: In Reply to Dr. Ten Kate.

IN the last number of Science, Dr. Ten Kate makes a series of strictures on the paper I read before the American Association for the Advancement of Science, entitled ' On the Alleged Mongoloid Affinities of the American Race.' These strictures close with some sentences which I should think a scientific mind would hesitate to write, as certainly a scientific mind will refuse to accept, - sentences to the effect that any one who differs from the opinions expressed by the writer of those strictures cannot believe in either anthropology or natural history. In spite of this egomet dixi, I venture to retain my opinion, and even to defend it.

But first let me state clearly what were the aim and limit of my paper.

These were simply that in our present state of knowledge there is no sufficient ground, either in language, in culture, or in ethnic anatomy, for the oft-repeated assertion that the American Indians belong to the Mongolian sub-species of the species Homo. What future researches may prove, such as those of Dr. Ten Kate, I do not pretend to say; and I distinctly avoided his example of basing present theories on imagined prospective discoveries (see his remarks in his footnote).

Some of his arguments are so extraordinary that they merit special attention. Notably so is that with reference to language. He makes the astounding assertion that we should group together languages because the nations speaking them present similar physical characteristics! I need but ask if there ever lived a scientific linguist to whom this novel system occurred. Dr. Ten Kate acknowledges, that, as yet, no linguistic connection has been shown between American languages and those of the Asiatic Mongols. This is all I asserted.

Nor does my critic attempt to show a single element of Mongolian culture in America. I maintain that this culture is autochthonous; it can all be accounted for by the sociologic history of the nations possessing it ; and when such is the case, it is totally unscientific to go elsewhere to seek its origin.

Dr. Ten Kate is most diffuse on somatologic points ; and on these he is singularly inconsistent. He argues that the color and character of hair and skin are of little or no importance as race distinction, adducing the Teutons and Italians as examples. I differ with him here, and I deny the correctness of his observations about the color of the American Indians; but grant his position, and does it not also prove the futility of those arguments based upon the alleged identities in these respects of Americans and Mongolians? In either case my thesis would stand intact.

With regard to the relative prevalence of the ossa Incce, I must retain my opinion until Dr. Ten Kate is more explicit in his figures, and the same with reference to the glabella. I am prepared to furnish statistics when called upon.

In his paragraph about brachycephaly the critic contradicts not one of my statements, although he asserts that he does. If I have anywhere said that there are no brachycephalic tribes in America,
I should like the passage pointed out. His references to half a dozen authors in this connection are meaningless. Why he finds himself under the necessity of pointing out the distinction between the nasal index as determined on the bony skull and the living face, I know not. American anthropologists do not require instruction in this elementary fact. If he had been familiar with Topinard's 'Elements d'Anthropologie,' to which he refers, and which I quoted in that connection, he would have known that any intimation that I had neglected that distinction was groundless.

I shall not pursue this reply further. The reader may decide whether Dr. Ten Kate has shown a single well-established affinity between the Americans and the Asiatic Mongols. I assert he has not ; and I add that such affinities are not möre numerous than between the Americans and, say, the Berber tribes of North Africa.

Media, Penn., Nov.

D. G. BRINTON, M.D.

\section{The Theory of the Origin of Species by Natural Selection.}

A REMARKABLY clear conception of the elements of the theory for which Charles Darwin has become famous was published almost thirty years prior to the appearance of 'The Origin of Species.'

I have just brought home with me from London a number of geological works published in the early part of this century, among them a copy of Robert Bakewell's 'Introduction to Geology.' The passage I am about to quote from it appeared first in the fourth edition, which was published in 1833 ; and it is repeated in the fifth edition, published in 1838 , with an interesting footnote (see pp. 403, 404).

The author is discussing Deshayes's classification of the various tertiary formations by means of comparison of the faunas with the living species. In the course of the discussion, he refers to the experiments of Robert Bakewell of Dishley, in Leicestershire, in producing choice breeds of sheep by artificial selection. He describes Mr. Bakewell's method as follows :-

" He first travelled over England, and part of the continent, to discover and select animals of the same species, possessing certain peculiarities of form, and other qualities which he was desirous to render permanent. By selecting two animals to breed from, which possessed the desired qualities in an eminent degree, and afterwards selecting from their offspring those in which these qualities were most conspicuous and breeding again from them, the peculiarities were further increased. By continuing the same selection through four or five generations, he obtained races that would transmit the same qualities permanently to succeeding generations."

Then the author applies this principle to explain the appearance of new forms of Mollusca in the tertiary beds, as follows :-

" Let us, however, imagine, what is very possible, that a number of individuals of one species of bivalve or univalve shell were driven, during a violent storm, into a distant part of the ocean, where the animals could no longer obtain their accustomed food, but were still able to support life by aliment of a somewhat different kind. Let us suppose that the annoyances to which they had before been subject, from natural enemies or other causes, were changed for annoyances of another kind. Under these different circumstances, is it not probable that the animals themselves would undergo some change, and modify the construction of their shells in some degree, to render them better suited to the new conditions in which they were placed? Thus, in the course of a few generations, we should have a race which conchologists would call a distinct species."

To this the author adds this footnote in the fifth edition (1838) : "What was above stated hypothetically in the fourth edition of this work may now be asserted as ascertained facts. Dr. Harlan, a distinguished American naturalist, informed the author that testaceous Mollusca removed from one river to another in America were observed in time to change the form of their shells. Mr. Gray, in the Philadelphia Transactions, I833, states that great varieties of form are produced in shells of the same species, by a removal from calm to agitated water."

Here the chief points of Darwin's theory of the origin of species are expressed. They are founded, also, upon observed facts. The 
results produced by artificial selection are taken as examples of what would take place in nature under the assumed circumstances ; and this "natural selection" is proposed as a sufficient explanation of the appearance of " a race which conchologists would call a distinct species."

The author states also, referring to Mr. Bakewell, "I have heard him say, that he scarcely knew any assignable limits beyond which these changes, both external and internal, might not be carried" (p. 402). Another statement is interesting as showing that Charles Darwin doubtless knew of this Mr. Bakewell, and may have heard him discuss these matters in his boyhood. In a footnote (p. 403) we read, "Mr. Bakewell of Dishley was in a considerable degree self-educated ; but he possessed a strong original mind, which was enlightened by study and meditation. He was also a man of great moral worth, and was intimately acquainted with Dr. Priestley, Dr. Darwin, and other eminent philosophers who inhabited the central part of England, towards the close of the last century. The late Countess of Oxford once asked the author of the present work, whether he was related to the $M r$. Bakewell who invented sheep. $\mathrm{He}$ replied that he was of the same Leicestershire, or originally Derbyshire family,"

It appears from these quotations that "the Mr. Bakewell who invented sheep," and the Mr. Bakewell, author of "Introduction to Geology,' were true Darwinists before Charles Darwin. And who can tell how much of Mr. Bakewell's theory of natural selection was transmitted to the youthful Darwin through the delicious mutton of the Leicestershire Downs?

H. S. Williams.

Cornell University, Nov. 3 .

\section{'Bi-daily.'}

THE Monthly Weather Revieze of the Signal Service for August contains the term 'bi-daily,' as applied to the present system of indications, which are now made twice each day. That this is an incorrect use of the prefix ' bi' may be discovered by consulting a dictionary, or by reflecting upon its derivation.

The prefix 'bi' doubles the word to which it is prefixed. A biennial election is a two-yearly election, i.e., once in two years; and a bi-daily observation is an observation made every two days.

An event occurring twice each day is half-daily or semi-daily, the same as a semi-annual dividend or a half-yearly payment.

The word 'tri-daily,' which is applied to the signal-service observations, has attained by usage the meaning 'three times a day,' because of the lack of any other simple prefix. But the extension of this improper usage to the prefix ' bi' can have no warrant, since we have the correct prefix 'half' or 'semi,' both of which are already in common use.

Geo. E. CURTis.

Topeka, Kan., Nov. I.

\section{Buffalo on the Texas Plains.}

THE re-opened discussion of the buffalo question calls for a few statements concerning these animals in Texas. Two hundred head or more of these animals may be found in the Panhandle of Texas, on the Llano Estacado, and in No-Man's Land. Some are on the Palo Duro Cañon ranch, owned by Capt. Charles Goodnight; others in the Texas Capital Syndicate, or XIT pasture, especially on the North Plains, i.e., north of the Canadian River; still others are at large. Probably twenty or more buffalo calves were captured this spring in that region and driven to Kansas for mercenary and breeding purposes. The cow-boy's ideal, like that of the more 'refined' sportsmen, is to shoot these cattle at sight, but the proprietors of the ranches are doing much for their protection.

There are also many buffalo on the South Plain. The antelope, black-tailed deer, and many rare but smaller mammals, are found in the same region - all of which I saw or heard of during a recent visit to Plaza Larga, Tucumcarri Mesa, and the Texas Panhandle. Naturalists desiring these forms should go to Tascosa. Tex., near the New Mexican line, a place easily accessible from Kansas, Denver, and Texas, via the Fort Worth and Denver Railway. The capture of wild horses is a profitable pursuit in this region.

University of Texas, Austin, Nov. 7 .
ROBT. T. HILL.

\section{Answers.}

37. What Numbers doEs it take to MAKE a Billion? -Responding to Query 37 (Science xii. 204), "What numbers make a billion?' I would offer the following remarks: The term 'billion' appears to have been introduced by the Italian arithrneticians early in the fourteenth century. Peacock, in his admirable history of arthmetic (Encyclopad. Metropol., vol i.), states that the Italians made " a great addition to their former numerical language by the use of the word 'millione' (which properly signifies 'great thousand ') to denote the square of one thousand; and which was followed by the words ' billione,' ' trillione,' etc., deduced immediately from the form by pursuing the natural analogies of the language : a series of numerical terms was thus formed, proceeding not by tens, but by millions." The new terms were slowly adopted by the nations of Europe, but in every case in their original and etymological sense.

In Spain these terms were used probably not long after their establishment in Italy; in France they were adopted not much before the opening of the sixteenth century; in Germany, early in the sixteenth century; in England, not till the close of the seventeenth century; and in Russia, early in the eighteenth century. Locke, who published his great essay in 1690 , complains that his countrymen were accustomed to speak of millions of millions of millions instead of using the more convenient term 'trillions ;' and he gives an example of the proper notation to sixty places of figures, divided into sextuple periods, and duly named up to nonillions. "The ordinary way of naming this number in English will be the often repeating of millions of millions of millions of millions," etc. (Human Understanding, book ii. chap. 16 , sect. 6). It is important to observe, that, wherever introduced, the term 'billion' uniformly designated the bis power of the million, - a value, the prefix to twelve places of figures. In the Italian dictionary of the Accademici della Crusca, the word 'bilione' (or 'billione') is defined, "un milione di milioni." In the Spanish dictionary of the Academia Española, the word 'billon ' is defined, "un millon de millones," or a million multiplied by itself. In the German dictionary of Dr. Daniel Sanders, "billion' is defined, "millional million." And in Littrés 'French Dictionary,' after defining the word, it is stated, "The forms billion, trillion, etc., were devised in the sixteenth century to signify periods of six to six figures : counting from the right, units were represented by the first six places of figures, the millions were represented by the figures from 7 th to the I 2 th places, the billions were represented by the figures from the I $3^{\text {th }}$ to the I8th places, and so on." Est. De La Roche's 'Arithmetique' is quoted as stating, "A billion is equal to a million million." Littré adds (without explanation), "It was not till the middle of the seventeenth century that the rule of separating into periods of six, was changed to separating into periods of three figures, and the original billion was divided by $\mathrm{I}, 000 . "$ It is not a little surprising that our compilers of school arithmetics (whether smitten with Francomania or with Anglo-phobia) have almost unanimously adopted the modern French perversion of the terms 'billion,' 'trillion,' etc. And thus business-men are in the habit of numerating '- illions' by places of three (after the million place), while astronomers and mathematicians preserve the original and logical numeration by places of six figures. It needs but a bare inspection of the terms themselves to see that this French neologism (of the last two centuries) is not only anomalous, but wholly irrational. The form of the words ' million,' ' billion,' ' trillion,' ' quadrillion,' ' quintillion,' etc., necessarily denotes some co-ordination of numerical progression. What can it possibly be on the pedagogue's system? The expression I 000, 000000 (one thousand million) does not admit any logarithmic bisection. How can it, then, be in any sense a billion? If it be any kind of a bis, what is its primary? It is an impossible second power, having a surd for its root. Had the French arithmeticians cut down at the same blow the million to the mille, the scheme would at least have been consistent. A true billion is evidently a second order of million, and the only rational order is the second power.

To any reflecting mind the school-book numeration is simply absurd, and its prevalence is a very puzzling phenomenon.

Washington, D.C., Oct. $3^{\circ}$. 